\title{
Histopathological spectrum of cholecystectomy specimens in a tertiary care hospital in Bangalore
}

\author{
Anushree C. N. ${ }^{1, *}$, Sunita B. Patil ${ }^{2}$, Sampath Kumar C. ${ }^{3}$, Shwetha Pallavi M. S. ${ }^{4}$, H. T. \\ Jayaprakash $^{5}$
}

${ }^{1,2}$ Associate Professor, ${ }^{3,4} \mathrm{PG}$ Student, ${ }^{5}$ Professor \& HOD, Dept. of Pathology, ${ }^{1,3,4,5}$ Dr. B. R. Ambedkar Medical College Bangalore, Karnataka, ${ }^{2}$ D. Y. Patil Medical College, Kolhapur, Maharashtra, India

*Corresponding Author:

Email: dranu77@gmail.com

\begin{abstract}
Introduction: Gallstone disease is a major health problem and puts notable burden on individuals and health care system worldwide. This research was carried out to study the varied histopathological changes in the gallbladder mucosa as a result of cholelithiasis.

Materials and Methods: The present research comprised 190 gallbladder specimens obtained from cholecystectomy procedures conducted at tertiary teaching hospital in Bangalore. The gross examination was done after fixing the specimens with $10 \%$ formalin. Haematoxylin and eosin was used to stain gallbladder sections from fundus, body and neck.

Results: On gross examination, congestion was noticed on surface of gall bladder in 67 cases (35.26\%), wall was thickened in more than half of cases $104(54.74 \%)$. Nearly a quarter of specimens showed pathological changes in mucosa of gallbladder $(23.15 \%)$. Histopathological examination observed evident epithelial hyperplasia in 80 cases $(42.1 \%)$, antral metaplasia in $20(10.5 \%)$, intestinal metaplasia in $12(6.3 \%)$, dysplasia with carcinoma in one case $(0.53 \%)$.

Conclusion: Gallstones produce a wide range of histopathological changes in mucosa and calls for dedicated attention of pathologist routinely.
\end{abstract}

Keywords: Cholelithiasis, Dysplasia, Hyperplasia, Metaplasia.

Received: $12^{\text {th }}$ May, 2017

\section{Introduction}

Gallstone disease is a fairly common condition at global level and constitutes more than $90 \%$ of biliary tract disease. ${ }^{1}$ Gallstones are known to cause significant morbidity and mortality in all parts of the world. ${ }^{2}$ Due to changes in dietary pattern with high calorie and high fat diet, and increased alcohol consumption the incidence of cholecystitis and cholelithiasis has shown an upward trend in the recent 3 to 4 decades $^{3,4}$ Gallstones prevalence is shown to vary with socio-demographic factors like age, sex and ethnic group. Majority remains unaware of the condition and lead asymptomatic course. ${ }^{2}$

Cholelithiasis is believed to cause varied histopathological changes in gall bladder mucosa like acute and chronic Inflammation, cholesterolosis, hyperplasia, metaplasia, dysplasia, and carcinoma., ${ }^{5,6}$ The objective of the present study was to evaluate the histopathological patterns of gall bladder diseases and their incidences in patients undergoing cholecystectomy for cholelithiasis.

\section{Materials and Methods}

This prospective study was based on 190 gallbladder specimens obtained from cholecystectomy procedures conducted at a tertiary teaching hospital in Bangalore, during 2 years period from March 2015 to February 2017. This study was conducted at Dr. B R Ambedkar medical college, Bangalore. The gross examination was done after fixing the specimens with $10 \%$ formalin. Gross morphological findings of size, external surface, thickness of wall and mucosa were noted. For each specimen, three sections were obtained for entire thickness of wall from fundus, body and neck of specimen. Supplementary sections were taken from abnormal appearing foci. Routine tissue processing was done. 4 micron thickness sections were obtained from paraffin embedded tissue followed by routine Haematoxylin \& Eosin staining and detailed microscopic evaluation. The data were entered and analyzed in MS Excel 2010 software and results presented in absolute numbers and percentages.

On microscopy, mucosa was examined for inflammation, cholesterolosis, hyperplasia, antral metaplasia, intestinal metaplasia, dysplasia and 
carcinoma. Presence of inflammation (acute/chronic/granulomatous/eosinophilic/xanth ogranulomatous), muscle hypertrophy and fibrosis in gall bladder wall was noted.

The following microscopic diagnostic criteria were used:

Cholesterolosis: Aggregates of cholesterol laden foamy macrophages.

Hyperplasia: Preudostratified epithelium, nuclear crowding, tall columnar cells.

Intestinal metaplasia: Presence of goblet cells.

Antral metaplasia: Mucous glands in lamina propria.

Dysplasia: Preudostratified epithelium, loss of polarity, nuclear crowding, nuclear atypia.

Carcinoma in situ: marked architectural atypia, full thickness marked nuclear atypia, atypical mitotic figures, absence of stromal invasion.

Carcinoma: Malignant glandular epithelium infiltrating into muscle layer along with desmoplastic change.

\section{Results}

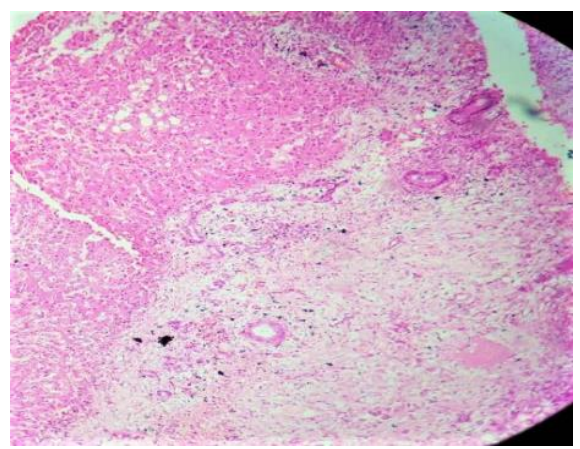

Fig. 1: Luschka ducts related to adjacent hepatic tissue

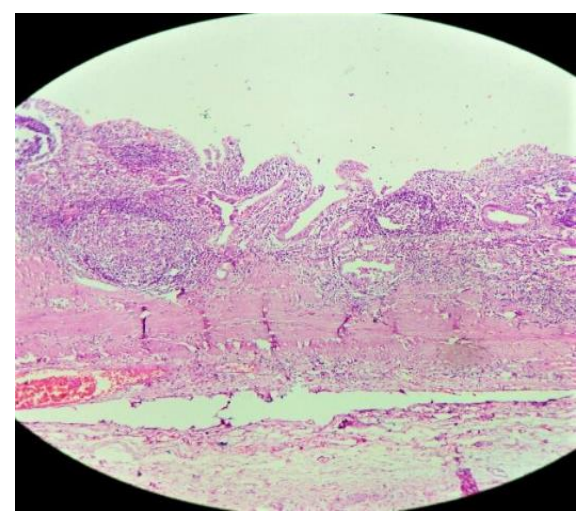

Fig. 2: Follicular cholecystitis

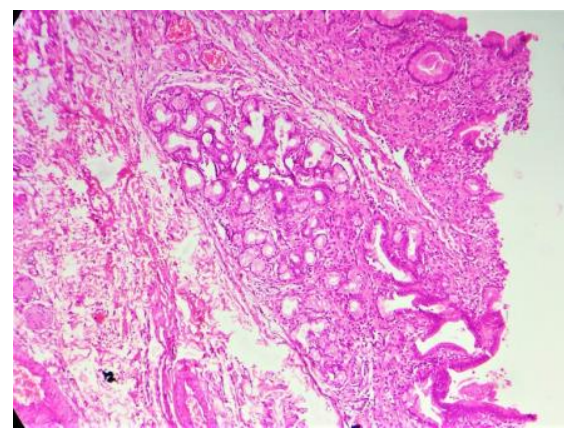

Fig. 3: Metaplastic change in mucosal epithelium

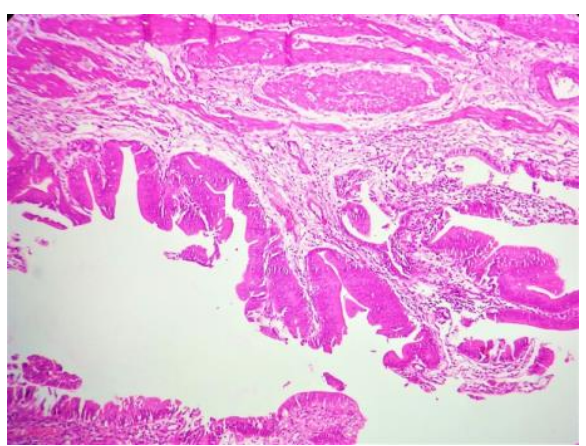

Fig. 4: Dysplasia in mucosal epithelium

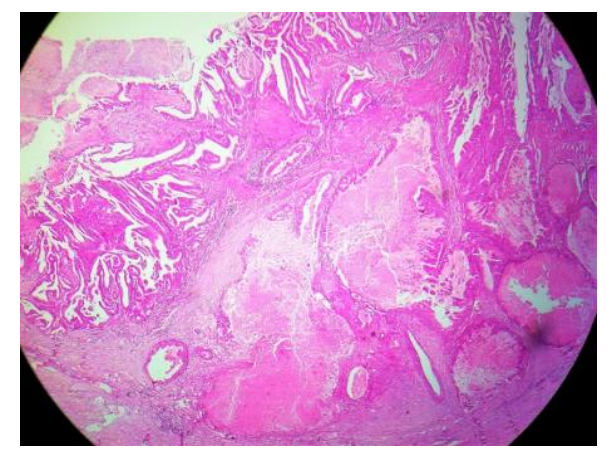

Fig. 5: Gallbladder Adenocarcinoma grade I

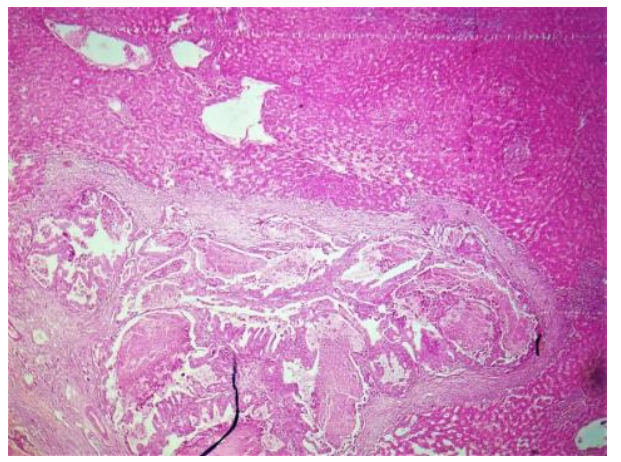

Fig. 6: Gallbladder Adenocarcinoma metastasized to Liver

A total of 190 cholecystectomy specimens were studied in two years duration. Female cases were twice the male cases (M:F ratio of 1:2.06). Age range of cases in the study was 21 to 82 years. Mean age was 43 years. Table-1 shows 
age and sex distribution of cases. Over half of the cases occurred in $4^{\text {th }}$ and $5^{\text {th }}$ decades of life.

Gall bladder size was normal in $118(62 \%)$, enlarged in $44(23 \%)$ and fibrotic in $28(15 \%)$ specimens. Table 2 shows the gross finding in gall bladder specimens. Surface of serosa was normal in $123(64.74 \%)$ and congestion was evident in 67 cases $(35.26 \%)$. Gallbladder wall was more than $3 \mathrm{~mm}$ in thickness (thickened) in more than half of specimens 104 (54.74\%). Mucosa appeared normal in majority of cases $(76.84 \%)$. The number of gall stones and chemical composition of stones did not reflect much on gross changes.

In Specimens with mixed histopathological features, the categorization into one diagnosis per case was based on major changes observed. Normal epithelium was seen in 33 (17.3\%), epithelial hyperplasia in $80(42.1 \%)$, antral metaplasia in $20(10.5 \%)$, intestinal metaplasia in $12(6.3 \%)$, coexisting dysplasia was seen in one case of carcinoma $(0.5 \%)$, and ulceration and fibrosis in 43 cases $(23 \%)$.

Table 1: Age and sex distribution of cases $(\mathrm{N}=190)$

\begin{tabular}{|c|c|c|c|}
\hline \multicolumn{2}{|c|}{ Characteristic } & No of cases & Percentage (\%) \\
\hline Gender & Male & 62 & 32.63 \\
\cline { 2 - 4 } & Female & 128 & 67.37 \\
\hline \multirow{4}{*}{$\begin{array}{c}\text { Age group } \\
\text { (in years) }\end{array}$} & $21-30$ & 26 & 13.68 \\
\cline { 2 - 4 } & $31-40$ & 46 & 24.21 \\
\cline { 2 - 4 } & $41-50$ & 52 & 27.37 \\
\cline { 2 - 4 } & $51-60$ & 40 & 21.05 \\
\cline { 2 - 4 } & $61-70$ & 22 & 11.58 \\
\hline
\end{tabular}

Table 2: Gross findings of Gall bladder specimens (N=190)

\begin{tabular}{|l|c|c|}
\hline Gross finding & No of cases & Percentage (\%) \\
\hline Serosa & 123 & $64.74 \%$ \\
\hline Normal & 67 & $35.26 \%$ \\
\hline Congested & 86 & $45.26 \%$ \\
\hline Wall & 104 & $54.74 \%$ \\
\hline Normal & 146 & $76.84 \%$ \\
\hline Thickened & 18 & $9.47 \%$ \\
\hline Mucosa & 26 & $13.68 \%$ \\
\hline Normal
\end{tabular}

Table 3 shows distribution of cases by histopathological diagnosis. Commonest diagnosis was chronic cholecystitis $(47.37 \%)$, followed by chronic cholecystitis with hyperplasia (21.05\%) and metaplasia $(16.84 \%)$.

One chronic cholecystitis case showed small tubular formations in the subserosal layer, on the hepatic side- Luschka ducts. These tubular structures are similar to Rokitansky-Aschoff sinuses, however, did not have any communication with them.

There was one case of well-differentiated conventional adenocarcinoma of gall bladder grade-1 in a 45 year old female. Dysplastic changes were present in the mucosa adjacent to the malignant foci. There was no lymphovascular and perineural invasion noted. However, metastatic deposits were noted in liver.

Table 3: Distribution of cases by histopathological diagnosis. ( $N=190)$

\begin{tabular}{|l|c|c|}
\hline \multicolumn{1}{|c|}{ Histopathological diagnosis } & $\begin{array}{c}\text { Number } \\
\text { of cases }\end{array}$ & $\begin{array}{c}\text { Percentage } \\
(\mathbf{\%})\end{array}$ \\
\hline Acute cholecystitis & 2 & 1.05 \\
\hline Chronic cholecystitis & 90 & 47.37 \\
\hline Acute on chronic cholecystitis & 6 & 3.16 \\
\hline Follicular cholecystitis & 3 & 1.58 \\
\hline Chronic cholecystitis with hyperplasia & 40 & 21.05 \\
\hline
\end{tabular}




\begin{tabular}{|l|c|c|}
\hline Chronic cholecystitis with metaplasia & 32 & 16.84 \\
\hline Chronic cholecystitis with cholesterolosis & 16 & 8.42 \\
\hline Adenocarcinoma of gallbladder & 1 & 0.53 \\
\hline
\end{tabular}

\section{Discussion}

Around $10-20 \%$ incidence range has been attributed to cholelithiasis at global level. ${ }^{7} \mathrm{~A}$ further wider range of incidence has been reported for Indian population $(2-29 \%){ }^{2}$ Female preponderance to gall stone disease was very clearly noted in our study, similar to the finding in several other studies. Few studies reported this ratio to be as high as four times to six times. ${ }^{8-10}$ inactive lifestyle and sex hormones have been incriminated in explaining the higher incidence of cholelithiasis for women in India. ${ }^{2}$ Maximum incidence was noted in $4^{\text {th }}$ and $5^{\text {th }}$ decades in our study and the mean age was 43 years. This is comparable to age and gall stone findings observed in few other studies. ${ }^{8-9,11} 41-50$ years of life ( $5^{\text {th }}$ decade) is reported to witness peak incidence. ${ }^{10}$ In our study we did not get any case that was younger than 20 years of age during the study period. Several repeated occurrences of acute cholecystitis is thought to lead to chronic cholecystitis and gallstones are thought to be the main triggering condition for this. ${ }^{12}$

Epithelial hyperplasia was the most common finding in the present study ( $42.1 \%)$, followed by metaplasia (16.8\%). This finding is similar to the observation in other studies. ${ }^{9,11}$ A small percentage of hyperplasias are believed to advance towards atypical hyperplasia, which further most likely progresses to carcinoma in situ and carcinoma. ${ }^{13}$ It is proposed that, gallstones, by way of causing mechanical irritation, progress primary cholelithiasis to secondary hyperplasia. ${ }^{14}$ Metaplasia was the second most common change seen in our study $(16.8 \%)$ and antral metaplasia being more common than intestinal metaplasia. A similar incidence of $16 \%$ was noted in khanna et al and mathur et al studies. ${ }^{9-10}$ However, frequency of metaplasia can be seen in more than half of the cases with gallstone disease as reported in few other studies. ${ }^{15-16}$ Metastatic epithelium is considered to be more prone to malignant transformation than normal epithelium. ${ }^{17}$ Normal epithelium and metastatic epithelium could be two pathways by which gallbladder cancer can result. ${ }^{17}$

Epithelial dysplasia was found in one case of carcinoma in the present study $(0.53 \%)$. Few other researchers noted dysplasia in $1.3 \%$ and $2.2 \%$ of cases in their studies. ${ }^{11,17}$ However, one study reported dysplasia at $8.5 \% .^{9}$ Discrepancy may be due to number of specimens in each study, and number of sections examined and also the severity of gall bladder cases presenting to different clinical settings.

On macroscopic examination, many in situ carcinomas are overlooked or missed, due to the fact that these are not clearly differentiable from cholecystitis on gross examination. The gall bladder wall thickness and mucosa may show mild changes or remain normal on gross. This poses difficulty for a pathologist who may have no standard guide as to where to take the representative section. This could be the reason for underestimation of the incidence of in situ carcinoma. ${ }^{9}$

Chronic cholecystitis with cholesterolosis was noted in $8.5 \%$ in the present study. Cholesterolosis was found in $13 \%$ to $14 \%$ cholelithiasis specimens in two other studies. ${ }^{11,18}$ There was no case of carcinoma in situ in the present study but one case of carcinoma was observed $(0.53 \%)$. A similar percentage of gall bladder carcinoma was noted in asymptomatic cases in another study $(0.57 \%)$. Studies have shown that incidental gallbladder carcinoma is found in about $0.5-1.1 \%$ of cholecystectomies for gall stone diseases. ${ }^{19-20}$ The incidence of gallbladder cancer is reported to be higher in certain geographic areas, like the Karachi to Kolkata belt in the Indian subcontinent. ${ }^{21-22}$ Reasons for different incidences in different studies could be due to geographical region, severity of cases presenting to different settings, number of sections taken to examine for each specimen and deviation from uniform criteria for classifying microscopic findings.

\section{Conclusion}

$\begin{array}{cccc}\text { Gallstones } & \text { present } & \text { with } & \text { varied } \\ \text { histopathological } & \text { changes } & \text { ranging } & \text { from }\end{array}$ inflammation to malignancy. Chronic cholecystitis is the commonest histopathological finding in in gall stone diseases. Hence, we recommend detailed histopathological evaluation of all cholecystectomy specimens for timely diagnosis and prompt intervention.

\section{References}

1. Zuhair M, Rana Mumtaz R. Histological Changes of Gall Bladder Mucosa: Correlation with Various Types of cholelethiasis. Iraqi J. Comm. Med., July. 2011;24(3):234-40.

2. Mohan H, Punia RPS, Dhawan SB, Ahal S, Sekhon MS. Morphological spectrum of gallstone 
disease in 1100 cholecystectomies in north India. Indian J Surg. 2005;67:140-2.

3. Carey MC. Pathogenesis of gall stone. Am J. Surg.1993;p410.

4. Sherlock S. Diseases of the liver and biliary system. Blackwell Scientific Publication, Oxford. 10th Edition, 1997;1-714.

5. Shukla HS, Avasthi K, Naithani YP. A clinicopathological study of the carcinoma of the gallbladder. Indian J Cancer. 1981;18:198-201.

6. Stancu M, Caruntu ID, Giusca S, Dobrescu G. Hyperplasia,metaplasia, dysplasia and neoplasia lesions in chronic cholecystitis - a morphologic study. Rom J Morphol Embryol. 2007;48:335-42.

7. Coelho JC, Bonilha R, Pitaki SA et al. Prevalence of gallstone in Brazilian population. Int Surg. 1999;84:25-8.

8. Sharma I, Choudhury D. Histopathological patterns of gall bladder diseases with special reference to incidental cases-a hospital based study. Int J Res Med Sci. 2015;3:3553-7.

9. Khanna R, Chansuria R, Kumar M, Shukla HS Histological changes in gallbladder due to stone disease. Indian J Surg. 2006;68:201-4.

10. Mathur SK, Duhan A, Singh S, Aggarwal M, Aggarwal G, Sen R, et al. Correlation of gallstone characteristics with mucosal changes in gall bladder. Trop Gastroenterol. 2012;33(1):39-44.

11. Baidya R, Sigdel B, Baidya NL.Histopathological changes in gallbladder mucosa associated with cholelithiasis. JPN.2012;2:224-5.

12. Albores-Saavedra J, Henson DE. Atlas of Tumor Pathology: Tumors of the Gallbladder and Extrahepatic Bile Ducts. Second Series. Fascicle 22. 2nd ed. Bethesda, MD: Armed Forces Institute of Pathology; 1986. p.28-3.

13. Albores-Saavedra J, Molberg K, Henson DE. Unusual malignant epithelial tumors of the gallbladder. Semin Diagn Pathol. 1996;13:32638.

14. Elfving G, Teir H, Degert H, Makela V. Mucosal hyperplasia in the gallbladder demonstrated by plastic models. Acta Pathol Microbiol Scand. 1969;77:384-8.

15. Yamigava $H$, Tamiyama $H$. Intestinal metaplasia - Dysplasia carcinoma squence of the gallbladder. Acta Pathol Jpn. 1986;36:989-97.

16. Martinez-Guzman-e, de-la Rosa-Bayan J. Neoplasma and dysplasia of the gallbladder and their relationship with lithiasis. A case control clinic pathological study. Rev Gastroenterol Mex. 1998;63:82-8.

17. Yamamoto YM, Nakajo S, Tahara E. Carcinoma of the gallbladder: The correlation between histogenesis and prognosis. Virchows Arch Pathol Anat. 1989;414:83-90.

18. Meirelles-Costa AL, Bresciani CJ, Perez RO, Bresciani BH, Siqueira SA, Cecconello I. Are Histological alterations observed in the gallbladder precancerous lesions? Clinics. 2010;65:143-50.

19. Halldestam I, Enell EL, Kullman E, Borch K. Development of symptoms and complications in individuals with asymptomatic gallstones. $\mathrm{Br} \mathrm{J}$ Surg. 2004;91:734-8.

20. Khoo JJ, Misron NA. A Clinicopathological Study Of Nine Cases Of Gallbladder Carcinoma in 1122 cholecystectomies in Johor, Malaysia. Malaysian J Pathol. 2008;30(1):21-6.

21. Sen U, Sankaranarayanan R, Mandal S, Ramanakumar AV, Parkin DM, Siddiqi M. Cancer patterns in eastern India: the first report of the Kolkata cancer registry. Int J Cancer. 2002;100:86-91.

22. Matthyssens LE, Ziol M, Barrat C, Champault GG. Routine surgical pathology in general surgery. Br J Surg. 2006;93:362-8. 